\section{A) Check for updates}

Cite this: Nanoscale, 2022, 14, 2296

\title{
In situ silver nanoparticle coating of virions for quantification at single virus level
}

\author{
Zsófia Bognár, (D) ${ }^{a, b}$ Marien I. de Jonge ${ }^{c}$ and Róbert E. Gyurcsányi (DD*a,b,d
}

Received 17th November 2021, Accepted 15th January 2022

DOI: $10.1039 / \mathrm{d} 1 \mathrm{nr} 07607 \mathrm{~h}$

rsc.li/nanoscale

\begin{abstract}
In situ labelling and encapsulation of biological entities, such as of single viruses, may provide a versatile approach to modulate their functionality and facilitate their detection at single particle level. Here, we introduce a novel virus metallization approach based on in situ coating of viruses in solution with silver nanoparticles (AgNP) in a two-step synthetic process, i.e. surface activation with a tannic acid - Sn(॥) coordination complex, which subsequently induces silver ion (I) reduction. The metalic coating on the virus surface opens the opportunity for electrochemical quantification of the AgNP-tagged viruses by nano-impact electrochemistry on a microelectrode with single particle sensitivity, i.e. enable the detection of particles oherwise undetectable. We show that the silver coating of the virus particles impacting the electrode can be oxidized to produce distinct current peaks the frequency of which show a linear correlation with the virus count. The proof of the concept was done with inactivated Influenza A (H3N2) viruses resulting in their quantitation down to the femtomolar concentrations (ca. $5 \times 10^{7}$ particles per $\mathrm{mL}$ ) using $50 \mathrm{~s}$ counting sequences.
\end{abstract}

\section{Introduction}

The use of abiotic materials to encapsulate or coat individual cells and other bioentities emerged as a versatile modality to tune and control their biological functionality and to protect them from external stress factors. ${ }^{1}$ However, beside modulating the inherent biological function abiotic materials can provide bioentities with new properties such as magnetism, electrical conductivity or fluorescence that can be further exploited in biosensing, bioelectronics, biocatalysis, facilitating also their manipulation and handling. ${ }^{2,3}$ Generally, there are three main approaches to coat cells with abiotic materials either partially or developing fully isolating shells:

- (i) Direct assembly of nanoparticles on the cell surface (e.g., using organic and inorganic precursors, ${ }^{4}$ noble metal particles, ${ }^{5-8}$ quantum-dots, ${ }^{9}$ magnetic nanoparticles, ${ }^{10,11}$ nanotubes and nanorods, ${ }^{12-14}$ graphene ${ }^{15,16}$ and graphene-oxide ${ }^{17}$ );

- (ii) Employing cell metabolism to attract coating building blocks (e.g., $\mathrm{Ca}^{2+}$ uptake can be applied to attract $\mathrm{Ca}^{2+}$ decorated gold nanoparticles onto the cell surface ${ }^{18}$ );

\footnotetext{
${ }^{a}$ Department of Inorganic and Analytical Chemistry, Budapest University of Technology and Economics, Müegyetem rkp. 3, H-1111 Budapest, Hungary. E-mail: gyurcsanyi.robert@vbk.bme.hu

${ }^{b}$ MTA-BME Lendület Chemical Nanosensors Research Group, Müegyetem rkp. 3, H-1111 Budapest, Hungary

${ }^{c}$ Section Paediatric Infectious Diseases, Laboratory of Medical Immunology, Radboud Center for Infectious Diseases, Radboud University Medical Center, Philips van Leydenlaan 15, 6525 EX Nijmegen, The Netherlands

${ }^{d}$ MTA-BME Computation Driven Chemistry Research Group, Müegyetem rkp. 3, H-1111 Budapest, Hungary
}

- (iii) In situ induced coating of targets ${ }^{2}$ (e.g. surface induced polymerization, ${ }^{19-21}$ silicification, ${ }^{22-26}$ gold particle formation by in situ reduction ${ }^{27}$ and metal-polyphenolic networks ${ }^{28-31}$ ).

Scaling down these encapsulation processes from cells to much smaller size viruses with different surface functionality is expected to be challenging. Such attempts were mostly made by using the virus as a well-defined size and shape template to generate abiotic nanomaterials. ${ }^{32-35}$ However, exactly because of their small size, the metal encapsulation may represent a convenient modality to increase the detection sensitivity of viruses to single particle level while opening also the prospects for more affordable means for quantitation. Presently, solution-based state of the art detection methods with single virus sensitivity such as nanoparticle tracking analysis (NTA), ${ }^{36-39}$ resistive pulse sensing (RPS) with nanopores, ${ }^{40-43}$ and various approaches based on hydrodynamic focusing (e.g. flow cytometry, $^{44-46}$ optical waveguides ${ }^{47,48}$ ) are either rather complex or may have insufficient sensitivity for viruses in the lower nanometer range. Therefore, here we explored the feasibility to encapsulate virions in situ in a metallic shell that is amenable to electrochemical oxidation and as such can enable their electrochemical detection at single particle level. Such nano-impact electrochemical methods requiring merely a microelectrode and a potentiostat have clear advantages in terms of cost-effectiveness and methodological simplicity. Our main hypothesis was that viruses can be encapsulated in a metallic shell and that the oxidation of this shell at a microelectrode surface will provide current pulses the frequency of which correlates with the virus count. Previous innovative 
attempts involved the detection of viruses in the presence of a redox mediator in the sample solution. In this case virions upon collision with the electrode surface cause current blocking events as it has been shown with murine cytomegalovirus by Dick et $a{ }^{49}{ }^{49}$ However, irreversible adsorption of viruses on the electrode surface may hamper the measurements, a problem that could be potentially also addressed by an abiotic encapsulation. Therefore, we investigated an abiotic metal coating where protective metallic encapsulation can be coupled with appropriate redox properties for nano-impact electrochemistry. This is supported by recent work of Compton and co-workers, showing that virus particles exposed to AgNP solution result in adsorption of AgNPs on the virus surface that could be detected and quantified by nano-impact coulometry. ${ }^{7}$ Here, in contrary to nanoparticle adsorption, which may cause an undesirably large background without separation, we focused on developing a fairly universal methodology based on an in situ surface-induced metallization chemistry. In this respect we took advantage of tannic acid (TA) a polyphenol compound that contain high levels of galloyl groups making possible the coordination of a range of metal ions. Owing to their high surface binding activity TA-metal ion films were shown to form on the surface of various substrate materials. ${ }^{30,50,51}$ This procedure was mainly attempted with $\mathrm{Fe}$ (III) ions to encapsulate cells, e.g. Park et al. ${ }^{28}$ used tannic acid$\mathrm{Fe}(\mathrm{III})$ complex for cytoprotective single-cell encapsulation. The reported artificial shell could be degraded on-demand, while protecting the cell from external stresses. ${ }^{28}$ A quasi-reversible electrochemistry of the shell was also reported that involves the irreversible oxidation of the phenolic ligand, and reversible reduction of the metal ions. However, the detection of $\mathrm{Fe}(\mathrm{III})-$ TA complex-based virus shells by nano-impact electrochemistry with extremely short contacting times was not successful, and therefore we searched for a redox system with higher heterogeneous electron transfer rate constant. While nano-impact electrochemistry enabled efficient quantification of a range of abiotic nanoparticles such as platinum, ${ }^{52-55}$ iridium-oxide, ${ }^{56,57}$ silver, ${ }^{58-64}$ gold,${ }^{65-67}$ including insulating ${ }^{68}$ and semi-conducting ${ }^{48}$ nanoparticles, the low oxidation potential of silver seemed the most appealing to pursue. Thus in this study, we demonstrate the in situ chemical coating of influenza A (H3N2) virus with Ag, coupled with nano-impact electrochemistry as a new approach to functionalize and detect virus particles.

\section{Experimental}

\section{Chemicals and materials}

Influenza A Udorn/307/72 (H3N2) virus was cultured in embryonated eggs as previously described. ${ }^{69}$ Filamented quartz capillaries with outer diameter: $1 \mathrm{~mm}$ and inner diameter: $0.7 \mathrm{~mm}$ (QF100-70-7.5) were obtained from Sutter Instrument Co. (Novato, CA). Polystyrene (PS) nanoparticles with $4 \mathrm{w} / \mathrm{v} \%$ concentration and $100 \mathrm{~nm}$ diameter were purchased from Life Technologies Corporation (Carlsbad, CA).
Tannic acid, $\mathrm{SnCl}_{2} \cdot 2 \mathrm{H}_{2} \mathrm{O}, \mathrm{AgNO}_{3}$, citric acid, $\mathrm{NaOH}, \mathrm{NH}_{4} \mathrm{OH}, 3-$ ( $N$-morpholino)propanesulfonic acid (MOPS) and phosphate buffered saline (PBS) + 0.05\% Tween 20 (PBST) buffers were obtained from Sigma-Aldrich. All solutions were prepared with deionized (DI) water (18.2 $\mathrm{M} \Omega \mathrm{cm}$ resistivity, Millipore).

\section{Modification of PS nanoparticles for modelling the virus system}

Five $\mu \mathrm{L}$ of the PS nanoparticles were purified with DI water (18.2 $\mathrm{M} \Omega \mathrm{cm}$ resistivity, Millipore) using centrifugation (30 000 rcf, $20 \mathrm{~min}$ ) (Centrisart G-26C, Sartorius). $5 \mu \mathrm{L}$ of the tannic acid solution $\left(40 \mathrm{mg} \mathrm{mL}{ }^{-1}\right)$ and $5 \mu \mathrm{L}$ of $\mathrm{SnCl}_{2} \cdot 2 \mathrm{H}_{2} \mathrm{O}(10 \mathrm{mg}$ $\mathrm{mL}^{-1}$ ) were added sequentially to $490 \mu \mathrm{L}$ colloidal suspension of the PS nanoparticles. Next the $\mathrm{pH}$ of the suspension was adjusted to 7.4 by adding $500 \mu \mathrm{L}$ of $20 \mathrm{mM}$ MOPS buffer. The resulting solution was mixed vigorously for 10 seconds, followed by incubation for 30 minutes resulting in the tannic acid and $\mathrm{Sn}^{2+}$ complex formation on the surface of the nanoparticles. The unreacted tannic acid and $\mathrm{Sn}^{2+}$ were separated in three subsequent washing steps with centrifugation (30000 rcf, $20 \mathrm{~min}$ ) to avoid later stage silver nanoparticle synthesis in solution phase. Diamminesilver(I) solution was prepared by dissolving $\mathrm{AgNO}_{3}(0.2463 \mathrm{~g})$ in $10 \mathrm{~mL}$ DI water and $\mathrm{NH}_{4} \mathrm{OH}$ (25\%) was added dropwise until the precipitate dissolved and then the solution was completed to $50 \mathrm{~mL}$ with deionized water. The PS nanoparticles coated with TA-Sn ${ }^{2+}$ complex were resuspended under ultrasonication in $1 \mathrm{~mL}\left[\mathrm{Ag}\left(\mathrm{NH}_{3}\right)_{2}\right]^{+}$solution to form $\mathrm{Ag}(0)$ by local reduction with $\mathrm{Sn}^{2+}$ on the surface of the PS nanoparticles $(10 \mathrm{~min})$. The reduction of the $\mathrm{Ag}^{+}$was followed by absorbance measurement through the subsequent formation of Ag-coated nanoparticles using NanoDrop 2000c spectrophotometer (Thermo Fischer Scientific). The silver encapsulated nanoparticles were centrifuged (10000 rcf, $10 \mathrm{~min}$ ) three times and washed with DI water to remove the unreacted $\left[\mathrm{Ag}\left(\mathrm{NH}_{3}\right)_{2}\right]^{+}$solution.

\section{In situ AgNP synthesis on the surface of influenza A (H3N2) virus}

The modification of the influenza A (H3N2) virus particles was performed as described for PS nanoparticles. However, the virus coated with $\mathrm{TA}-\mathrm{Sn}^{2+}$ coordination complex was further purified using a Vivaspin 500 centrifugal concentrator (15 000 rcf, $10 \mathrm{~min}$ ) with 100000 MWCO to remove the unadsorbed coordination complex while the PES (polyethersulfone) membrane retained the modified virus particles. After resuspension of the virus in $\left[\mathrm{Ag}\left(\mathrm{NH}_{3}\right)_{2}\right]^{+}$solution the $\mathrm{Ag}$ ion reduction on the surface of the particles was performed, and the silver encapsulated virus particles were centrifuged three times in Vivaspin 500 (15 $000 \mathrm{rcf}, 10 \mathrm{~min}$ ) and washed with DI water.

\section{Nanoparticle tracking analysis}

NTA measurements were performed using Nanosight LM10-HS system (Malvern Instruments Ltd) equipped with a $488 \mathrm{~nm}$ laser light source and a sCMOS camera (Hamamatsu Photonics) triggered by the laser. Particles were diluted in DI water to a nominal concentration of $10^{8}$ particles per $\mathrm{mL}$ and 
were injected with a sterile syringe in the thin layer measurement cell. All measurements were performed at room temperature and at optimized camera level (shutter and gain). Results were evaluated as an average of ten track records, each of $30 \mathrm{~s}$ duration. Nanosight NTA 2.3 software was used for concentration determination, normalized intensity calculation and size distribution analysis.

\section{Amperometric nano-impact measurements}

Nanoparticle suspensions were diluted in $100 \mathrm{mM}$ sodiumdihydrogen-citrate $(\mathrm{pH}=3.9)$ solution. For nanoparticle counting experiments a HEKA EPC 10 USB patch-clamp amplifier (HEKA Elektronik) with a low/noise headstage, $4 \mathrm{kHz}$ low-pass filter and $50 \mathrm{kHz}$ sampling rate were used. For nano-impact electrochemistry measurements a carbon fiber microelectrode with $11 \mu \mathrm{m}$ diameter (MF-2007, BASi®) and a Ag/AgCl quasireference electrode (QRE) were immersed in the deoxygenated sample solution. The potential was held at $-500 \mathrm{mV}$ ( $v s$. QRE) for reducing the in situ synthetized, partly oxidized and passivated silver nanoparticles for $50 \mathrm{~s}$, followed by applying $+600 \mathrm{mV}$ (vs. QRE) oxidizing potential for $50 \mathrm{~s}$ for nano-impact measurements. The resulted current spikes originated from the random collision of the AgNP-tagged viruses with the microelectrode surface. The number of impacts were correlated with the silver tagged virus concentration. Current spikes were analyzed using a peak detection algorithm using a custom-written Python-software. ${ }^{70}$ For each measurement the number of the detected peaks was determined including the time of current spike, the full width at half maximum and the current amplitude. All results were calculated from ten repetitive measurements of $c a .50 \mathrm{~s}$ duration.

\section{Resistive-pulse sensing measurements}

Nanopipets with desired diameter around $400 \mathrm{~nm}$ were fabricated with a P-2000 micropipette puller (Sutter Instruments) using quartz capillaries with internal filament. A two-step pulling program was used: Cycle 1: Heat 750; Filament 4; Velocity 55; Delay 132; Pull 55 and Cycle 2: Heat 800; Filament 4; Velocity 30; Delay 129; Pull 120. The nanopipets were filled with PBST solution and were inserted into a pipet holder that included a $\mathrm{Ag} / \mathrm{AgCl}$ wire and a pressure port. The latter served to draw inside the sample solution through the tip during RPS by applying a negative pressure of $c a$. $900 \mathrm{~Pa}$. The nanopipet was immersed into a custom-made cell filled with the sample solution, diluted in PBST to a nominal concentration of $10^{9} \mathrm{~mL}^{-1}$. For counting measurements, the previously mentioned HEKA EPC 10 USB patch-clamp amplifier was used. The diameter of the nanopipets were determined based on electrical resistance measurements, i.e., the resistance was calculated from the current change upon applying two $10 \mathrm{~ms}$ duration squarewave pulses with $\pm 10 \mathrm{mV}$ amplitude. For virus counting a constant $+400 \mathrm{mV}$ voltage was applied using a $8.7 \mathrm{kHz}$ lowpass filter and $50 \mathrm{kHz}$ sampling rate. The current transients were evaluated by a custom-made Python-software as published previously. ${ }^{70}$

\section{Scanning electron microscopy (SEM) investigations}

SEM images of silver-modified and unmodified particles spotted onto a gold substrate were captured using a Thermo Scientific Scios ${ }^{\mathrm{TM}} 2$ DualBeam $^{\mathrm{TM}}$ SEM system at $5 \mathrm{keV}$ beam energy.

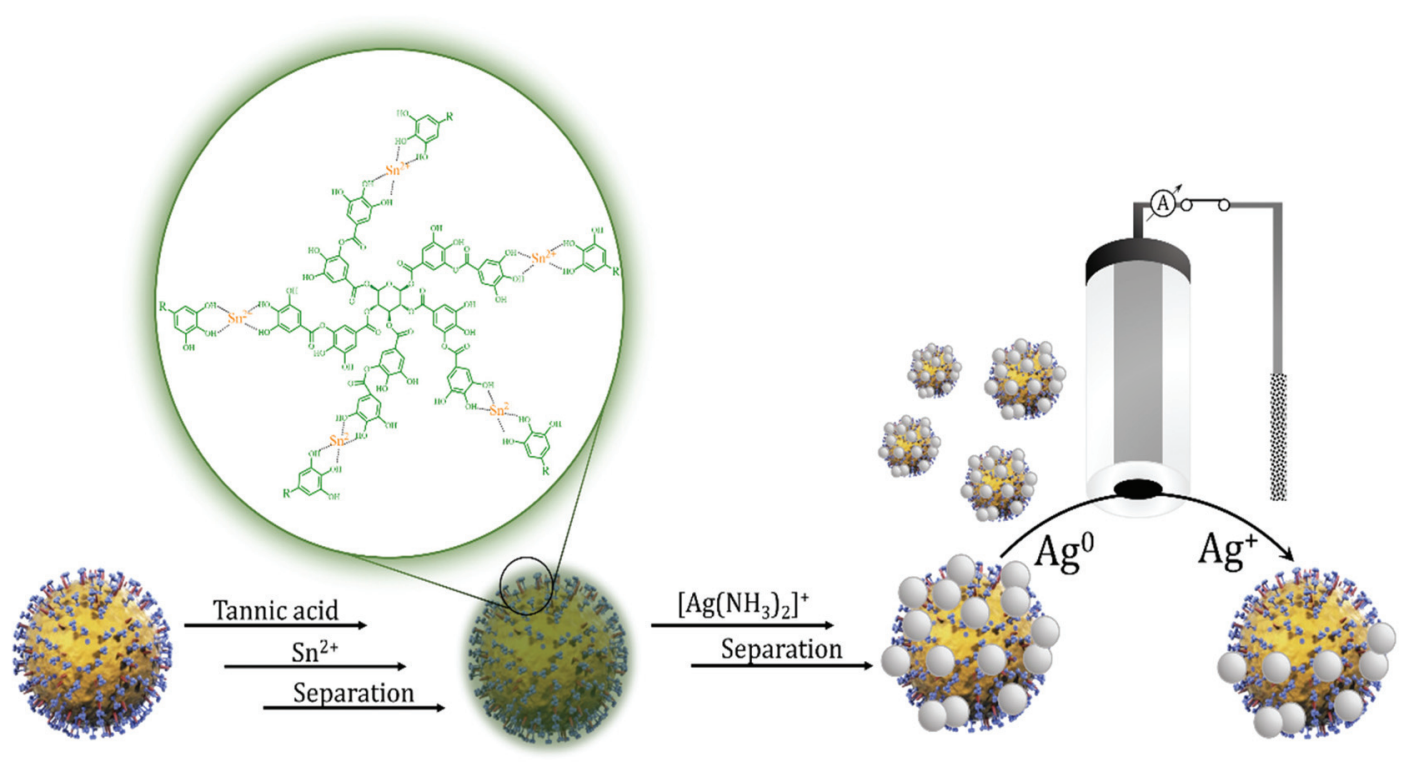

Scheme 1 Schematic workflow of the in situ AgNP coating of virions for amperometric nano-impact measurements. The surface of the virions was first activated with tannic acid- $\mathrm{Sn}^{2+}$ complex, followed by their separation from the reagent solution. The activated virus particles were then suspended in $\left[\mathrm{Ag}\left(\mathrm{NH}_{3}\right)_{2}\right]^{+}$solution with concomitant reduction of silver on the virus surface. This silver coating enables through its amperometric oxidation the quantification of virions at single particle level. 


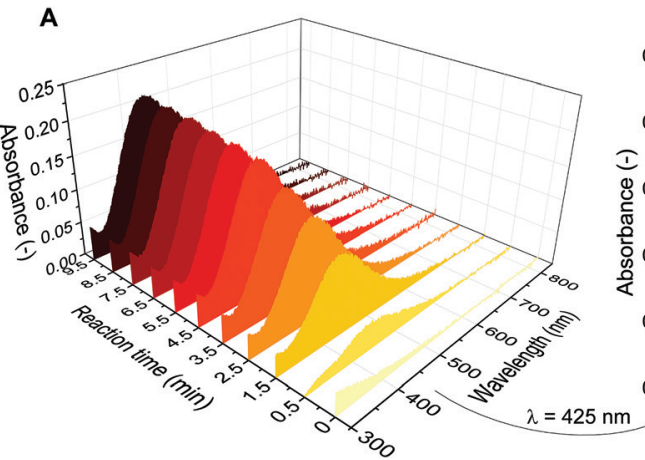

B

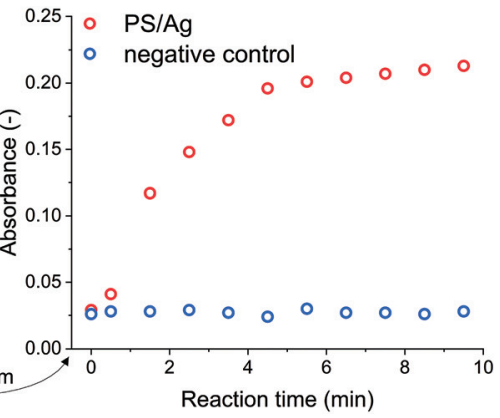

C

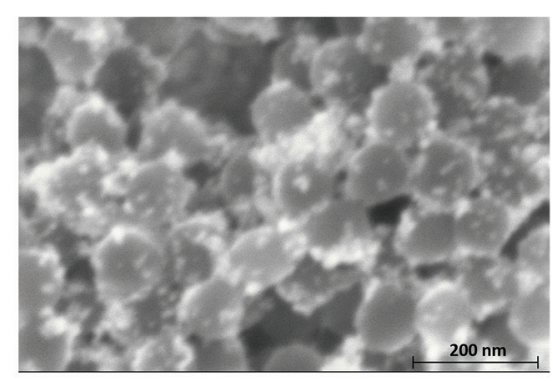

Fig. 1 Time dependence of the absorbance spectra indicative of in situ silver nanoparticle formation on the surface of the PS nanoparticles (A) as result of tannic-acid-Sn ${ }^{2+}$ coordination complex activation, followed by $\mathrm{Ag}^{+}$reduction. (B) The relevant absorbance values of the $\mathrm{Ag}$-coated nanoparticles at $425 \mathrm{~nm}$ (the characteristic absorption wavelength of AgNPs). The reaction terminated in five minutes, without the aggregation of the nanoparticles. (C) SEM images of AgNP-tagged nanoparticles shown at $150000 \times$ magnification.

\section{Results and discussion}

The overall concept to encapsulate viruses in a nanoparticulate silver shell that was expected to be amenable to electrochemical oxidation during their collision with a properly polarized microelectrode is shown in Scheme 1. The essential enabling technology in this respect is the two-step synthesis of the Ag layer on the surface of virus particles that involves first the formation of the tannic acid- $\mathrm{Sn}^{2+}$ coordination complex on the virus surface, which is inducing the reduction of $\mathrm{Ag}^{+}$in the subsequent step.

\section{In situ silver coating of the surface of polystyrene nanoparticles}

The surface induced coating of particles with silver was first tested using PS nanoparticles. The time dependence of the silver(I) reduction was examined with UV-VIS spectroscopy based on the appearance of the characteristic absorption band corresponding to the plasmonic resonance of the silver nanoparticles. The addition of the purified PS nanoparticles activated with tannic acid-Sn ${ }^{2+}$ coordination complex to the $\left[\mathrm{Ag}\left(\mathrm{NH}_{3}\right)_{2}\right]^{+}$ solution generated localized silver nanoparticles on the particle surface. As it can be seen on the UV-VIS spectra (Fig. 1A) the absorbance at $425 \mathrm{~nm}$ increased without any significant wavelength shift that suggests the absence of aggregation. It also indicates AgNP formation instead of a fully encapsulating layer, which was confirmed by SEM measurements (Fig. 1C) that also revealed mostly distinct single AgNPs coating the surface. The absorbance reached saturation very fast, in $5 \mathrm{~min}$, indicating the termination of the AgNP formation reaction (Fig. 1B). A negative control in which the PS nanoparticle surface was not modified with tannic acid- $\mathrm{Sn}^{2+}$ coordination complex confirmed no detectable silver formation in the absence of surface-activated particles. Thus the deposition occurs selectively on the surface of the activated particles.

\section{In situ silver coating of influenza A (H3N2) virus}

The method worked out for PS nanoparticles could be seamlessly adapted for Influenza A (H3N2) virus particles. As in case of PS nanoparticles the reaction resulted in a nanoparticle coating rather than a continuous silver layer. The equivalent diameter increase as result of the silver coating was confirmed using both NTA and RPS as shown in Fig. 2A and B, respectively.

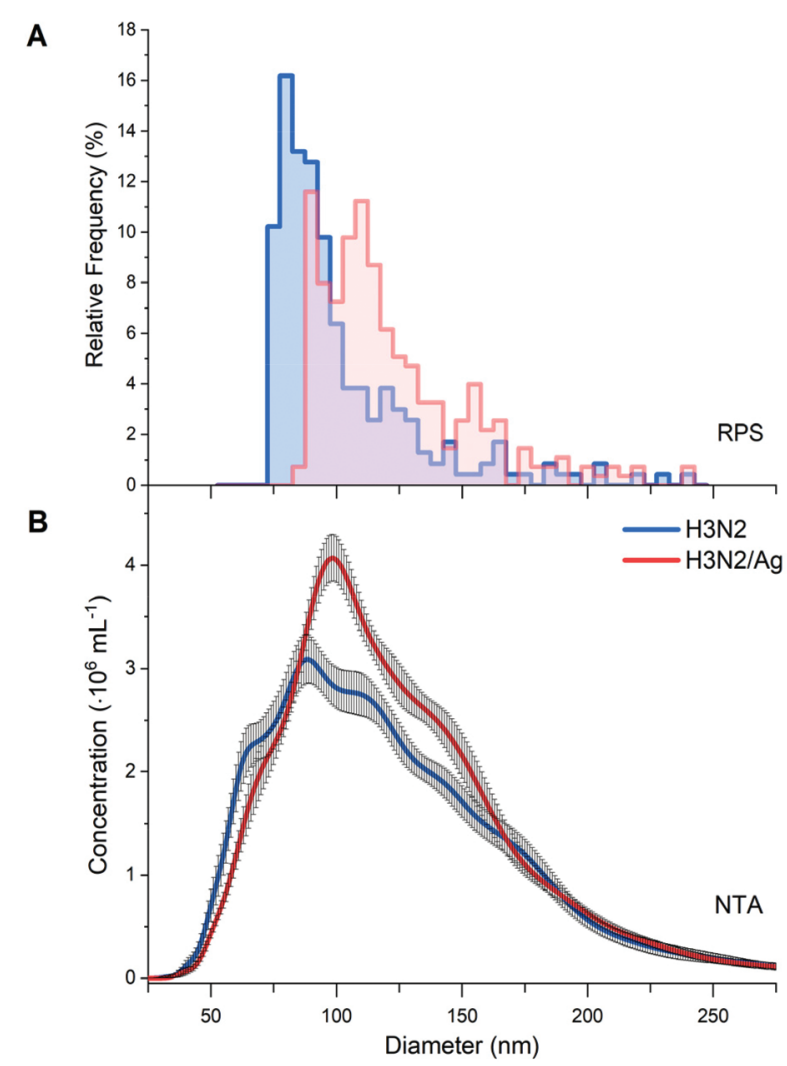

Fig. 2 Size distribution of untagged (blue) and AgNP-tagged (red) H3N2 influenza virus. NTA (A) and RPS (B) measurements show a good correlation in terms of size increase as result of the silver nanoparticle formation on the virus surface. NTA was performed in $\sim 10^{8} \mathrm{~mL}^{-1}$ while RPS measurements in $\sim 10^{9} \mathrm{~mL}^{-1}$ virus particle solution. The RPS measurements were made, with a $469.5 \pm 35.5 \mathrm{~nm}$ diameter pipet, at $+400 \mathrm{mV}$ (vs. Ag/AgCl) and 900 Pa negative pressure. 


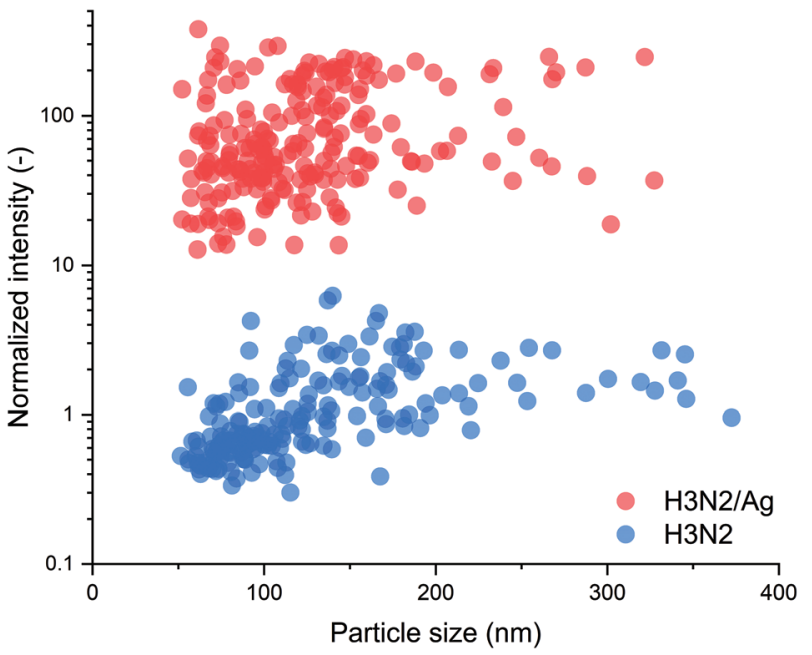

Fig. 3 Comparative 2D plot of the scattered light intensity of AgNPtagged and untagged virus particles at a concentration of $10^{8} \mathrm{~mL}^{-1}$ as determined by NTA.
The influenza A (H3N2) virus, like envelope viruses in general, is pleomorphic that explains the relatively broad size distribution. However, there is a clear shift of the equivalent diameter, ca. $88 \mathrm{~nm}$, with $c a .10 \mathrm{~nm}$ due to the silver coating of the virus surface. Owing to the separation of the unabsorbed TA-Sn(II) complex from the surface-activated virus after the activation step, bulk phase AgNP formation was not observed. This is clearly indicated by the absence of AgNPs with diameters lower than $50 \mathrm{~nm},{ }^{71}$ showing that silver nanoparticle formation and growth is induced by the virus surface. We expected that the silver coating will not only change the size of native virus particles, but owing to the metallization also the refractive index. This change may be more sensitively detected than the size change through an increase in the scattered light intensity of the Ag-covered virus particles. Of note, to detect the increase in the particle size would have not been trivial with ensemble methods and needed the extraordinary resolving power of single particle detection techniques as NTA and RPS. The change in the refractive index upon silver coating could be revealed in NTA through a significant increase in the scattered light intensity of the individual virus particles as shown in Fig. 3.

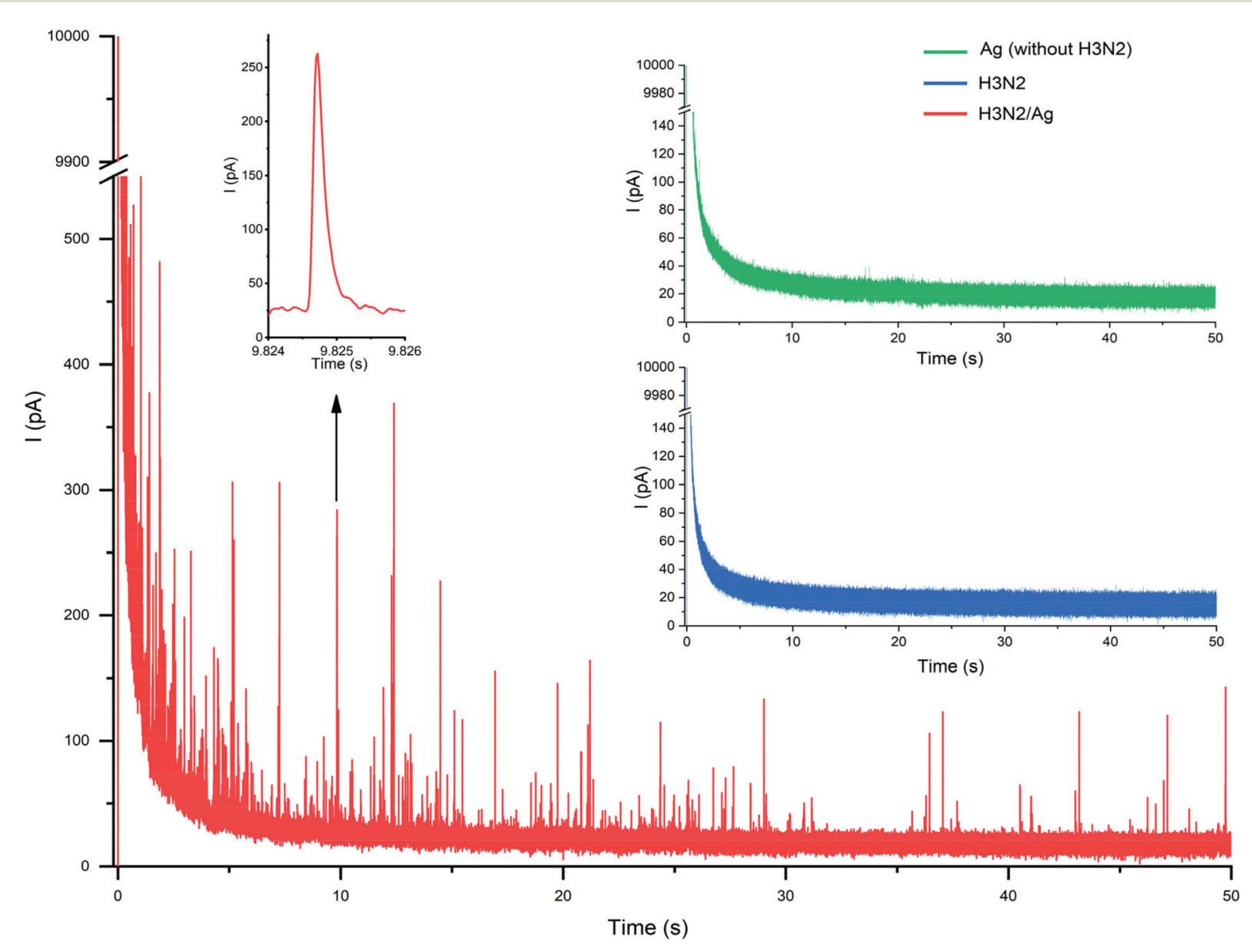

Fig. 4 Representative current transients during nano-impact electrochemistry of individual in situ AgNP-tagged H3N2 viruses and the magnified current signal of a single current spike. The inset shows as control the same experiment performed with unmodified H3N2 influenza virus particles and AgNP synthesis in the absence of H3N2 that reveal the full lack of any current spike. 
Remarkably, the normalised light scattering intensity allows explicit discrimination of the AgNP particle tagged viruses from untagged virions in the whole size range. While this further confirms the surface induced silver deposition, it can be exploited for more sensitive NTA measurements.

\section{Quantification of influenza A virus with nano-impact electrochemistry}

First we investigated the effect of the applied potential on the oxidation of Ag-covered nanoparticles. During nano-impact electrochemistry the nanoparticles undergo stochastic collisions with the microelectrode surface leaving very short times for the oxidation of the $\mathrm{Ag}$ shell. Indeed, the corresponding oxidative current peaks had half widths of $c a .1 \mathrm{~ms}$ (Fig. 4 inset) and therefore the applied potential should maximize the efficiency of the oxidation indicated by the frequency of the current spikes. We found that as the potential was increased from $200 \mathrm{mV}$ the frequency of the current spikes corresponding to individual particle-microelectrode collisions increased and finally levelled at $+600 \mathrm{mV}$ (vs. QRE) (Fig. 5 inset). Thereby, the applied potential in all further nanoimpact electrochemistry experiments was $600 \mathrm{mV}$, which was in agreement to the oxidizing potential reported by Compton. ${ }^{7}$

A typical recording during a nano-impact electrochemistry experiment performed in a AgNP encapsulated influenza A virus solution $\left(1.4 \times 10^{9}\right.$ particles per $\left.\mathrm{mL}\right)$ is shown in Fig. 4 .

The negative control experiments involving unmodified virus particles and samples in which the synthetic procedure was made in the absence of the influenza A (H3N2) virus did

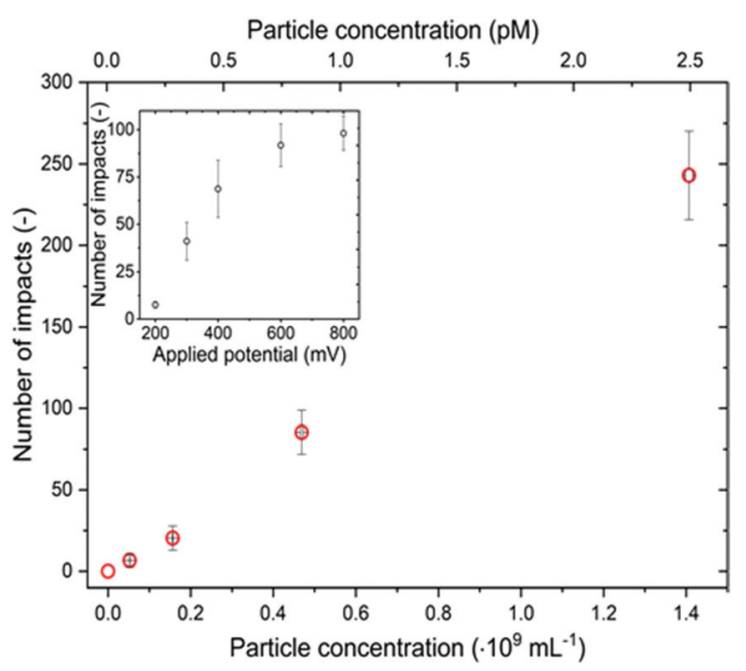

Fig. 5 The relation between the impact count and the AgNP tagged virus particle concentration as determined by nano-impact electrochemistry at an applied voltage of $+600 \mathrm{mV}$ vs. $\mathrm{Ag} / \mathrm{AgCl}$. The inset shows the optimization of the applied potential, showing saturation at $600 \mathrm{mV}$. The measurements were made using a carbon fiber microelectrode $(\varnothing 11 \mu \mathrm{m})$ in $100 \mathrm{mM}$ sodium-dihydrogen-citrate solution $(\mathrm{pH}=$ 3.9). The two horizontal axis show the same virus concentrations expressed in different units. The $\mathrm{pM}$ concentrations were calculated as $1000 \times$ viral particles $/\left(\mathrm{mL} \times N_{\mathrm{A}}\right)$, where $N_{\mathrm{A}}$ is the Avogadro number. not reveal any current spikes (Fig. 4 insets). These results confirm that the detected current events in the nano-impact electrochemistry measurements are due to the oxidation of AgNP-tagged virus particles and there is no Ag particle formation in the absence of the surface-activated virus particles acting as "nucleation centers". This contours as major benefit of in situ metallization as compared with direct modification with metal nanoparticles. We obtained a linear correlation between the number of impacts and the Ag-tagged virus concentration spanning over more than an order of magnitude as shown in Fig. 5.

The uncertainty of the measurements was much lower than previously reported for AgNP uptake-based tagging of viruses, ${ }^{7}$ which might be due to the relatively even distribution of the AgNPs on the particle surface, i.e. such in situ deposition might be less affected by local particle aggregation on the virus surface. This is supported by the relatively narrow charge distribution obtained by integration of the current spikes, 5.90 $\pm 1.80 \times 10^{-14} \mathrm{C}$. The smallest concentration of the AgNPtagged influenza A virus that could be detected using a $50 \mathrm{~s}$ time frame for the analysis was $5.2 \times 10^{7}$ particles per $\mathrm{mL}(86.5$ $\mathrm{fM}$ ), which is competitive with other state of the art single virus detection electrochemical methods such as RPS. ${ }^{72,73}$

\section{Conclusions}

Here we have proven the feasibility of in situ AgNP coating of viruses mediated by coordination complexation to enable their detection at single particle level with nano-impact electrochemistry using as a model the influenza A (H3N2) virus. At present this method is intended as a general metallization strategy to enhance the sensitivity and foster detectability rather than a mean for selective virus detection. Even at the proof of concept level the advantages of metallization are clear for both optical (NTA) and nano-impact electrochemistry methods. In case of NTA, the metallization may be of significance for very small viruses $(<30-50 \mathrm{~nm})$ with hardly detectable light scattering, which can be enhanced by the metal coating. Most importantly, however, the electrochemically active coating enables the direct and simple detection of viruses with a microelectrode. In this respect, the present coating methodology, most likely because of a more even distribution of the AgNP on the virus surface seems to result in significantly improved precision with respect of the state of the art. While the present approach is largely limited to rather pure virus formulations, e.g. vaccines, the methodology may be further developed for selective deposition.

\section{Author contributions}

Zsófia Bognár: investigation, methodology, data curation, formal analysis, visualization, writing - original draft. Marien I. de Jonge: methodology, writing - review \& editing. Róbert E. Gyurcsányi: conceptualization, methodology, supervision, visu- 
alization, writing - original draft, writing - review \& editing, funding acquisition.

\section{Conflicts of interest}

There are no conflicts to declare.

\section{Acknowledgements}

This research was funded by the National Research, Development, and Innovation Fund of Hungary under Grant TKP2021-EGA-02. Soma Papp is greatly acknowledged for assisting with resistive pulse sensing measurement. The authors are grateful to Dr Péter Fürjes and Levente Illés for the scanning electron microscopy measurements. We thank Marc Eleveld for the production of inactivated influenza A (H3N2) virus.

\section{References}

1 J. H. Park, D. Hong, J. Lee and I. S. Choi, Acc. Chem. Res., 2016, 49, 792-800.

2 B. Dai, L. Wang, Y. Wang, G. Yu and X. Huang, ChemistrySelect, 2018, 3, 7208-7221.

3 W. Geng, L. Wang, N. Jiang, J. Cao, Y. X. Xiao, H. Wei, A. K. Yetisen, X. Y. Yang and B. L. Su, Nanoscale, 2018, 10, 3112-3129.

4 B. Wang, P. Liu, W. Jiang, H. Pan, X. Xu and R. Tang, Angew. Chem., Int. Ed., 2008, 47, 3560-3564.

5 S. C. Hayden, G. Zhao, K. Saha, R. L. Phillips, X. Li, O. R. Miranda, V. M. Rotello, M. A. El-Sayed, I. SchmidtKrey and U. H. F. Bunz, J. Am. Chem. Soc., 2012, 134, 69206923.

6 M. Kahraman, A. I. Zamaleeva, R. F. Fakhrullin and M. Culha, Anal. Bioanal. Chem., 2009, 395, 2559-2567.

7 L. Sepunaru, B. J. Plowman, S. V. Sokolov, N. P. Young and R. G. Compton, Chem. Sci., 2016, 7, 3892-3899.

8 L. Sepunaru, K. Tschulik, C. Batchelor-McAuley, R. Gavish and R. G. Compton, Biomater. Sci., 2015, 3, 816-820.

9 C. Yang, H. Xie, Q. C. Li, E. J. Sun and B. L. Su, J. Colloid Interface Sci., 2015, 450, 388-395.

10 M. Martín, F. Carmona, R. Cuesta, D. Rondón, N. Gálvez and J. M. Domínguez-Vera, Adv. Funct. Mater., 2014, 24, 3489-3493.

11 R. F. Fakhrullin, J. García-Alonso and V. N. Paunov, Soft Matter, 2010, 6, 391-397.

12 X. Chen, U. C. Tam, J. L. Czlapinski, G. S. Lee, D. Rabuka, A. Zettl and C. R. Bertozzi, J. Am. Chem. Soc., 2006, 128, 6292-6293.

13 S. A. Konnova, I. R. Sharipova, T. A. Demina, Y. N. Osin, D. R. Yarullina, O. N. Ilinskaya, Y. M. Lvov and R. F. Fakhrullin, Chem. Commun., 2013, 49, 4208-4210.

14 V. Berry, A. Gole, A. Kundu, C. J. Murphy and R. F. Saraf, J. Am. Chem. Soc., 2005, 127, 17600-17601.
15 R. Kempaiah, W. L. Chung and V. Maheshwari, ACS Nano, 2011, 5(7), 6025-6031.

16 R. Kempaiah, S. Salgado, W. L. Chung and V. Maheshwari, Chem. Commun., 2011, 47, 11480-11482.

17 S. H. Yang, T. Lee, E. Seo, E. H. Ko, I. S. Choi and B. S. Kim, Macromol. Biosci., 2012, 12, 61-66.

18 V. Maheshwari, D. E. Fomenko, G. Singh and R. F. Saraf, Langmuir, 2009, 26, 371-377.

19 A. S. Mao, J.-W. Shin, S. Utech, H. Wang, O. Uzun, W. Li, M. Cooper, Y. Hu, L. Zhang, D. A. Weitz and D. J. Mooney, Nat. Mater., 2016, 16, 236-243.

20 J. Y. Kim, B. S. Lee, J. Choi, B. J. Kim, J. Y. Choi, S. M. Kang, S. H. Yang and I. S. Choi, Angew. Chem., Int. Ed., 2016, 55, 15306-15309.

21 J. Niu, D. J. Lunn, A. Pusuluri, J. I. Yoo, M. A. O’Malley, S. Mitragotri, H. T. Soh and C. J. Hawker, Nat. Chem., 2017, 9, 537-545.

22 D. Hong, H. Lee, E. H. Ko, J. Lee, H. Cho, M. Park, S. H. Yang and I. S. Choi, Chem. Sci., 2015, 6, 203-208.

23 H. Lee, D. Hong, J. Y. Choi, J. Y. Kim, S. H. Lee, H. M. Kim, S. H. Yang and I. S. Choi, Chem.-Asian J., 2015, 10, 129132.

24 J. H. Park, I. S. Choi and S. H. Yang, Chem. Commun., 2015, 51, 5523-5525.

25 S. H. Yang, K. B. Lee, B. Kong, J. H. Kim, H. S. Kim and I. S. Choi, Angew. Chem., Int. Ed., 2009, 48, 9160-9163.

26 S. H. Yang, E. H. Ko, Y. H. Jung and I. S. Choi, Angew. Chem., Int. Ed., 2011, 50, 6115-6118.

27 W. S. Kuo, C. M. Wu, Z. S. Yang, S. Y. Chen, C. Y. Chen, C. C. Huang, W. M. Li, C. K. Sun and C. S. Yeh, Chem. Commun., 2008, 4430-4432, DOI: 10.1039/b808871c.

28 J. H. Park, K. Kim, J. Lee, J. Y. Choi, D. Hong, S. H. Yang, F. Caruso, Y. Lee and I. S. Choi, Angew. Chem., Int. Ed., 2014, 53, 12420-12425.

29 P. V. Cherepanov, M. A. Rahim, N. Bertleff-Zieschang, M. A. Sayeed, A. P. O’Mullane, S. E. Moulton and F. Caruso, ACS Appl. Mater. Interfaces, 2018, 10, 58285834.

30 J. Guo, Y. Ping, H. Ejima, K. Alt, M. Meissner, J. J. Richardson, Y. Yan, K. Peter, D. von Elverfeldt, C. E. Hagemeyer and F. Caruso, Angew. Chem., Int. Ed., 2014, 53, 5546-5551.

31 W. Zhu, J. Guo, S. Amini, Y. Ju, J. O. Agola, A. Zimpel, J. Shang, A. Noureddine, F. Caruso, S. Wuttke, J. G. Croissant and C. J. Brinker, Adv. Mater., 2019, 31, 1900545.

32 K. M. Bromley, A. J. Patil, A. W. Perriman, G. Stubbs and S. Mann, J. Mater. Chem., 2008, 18, 4796-4801.

33 C. E. Fowler, W. Shenton, G. Stubbs and S. Mann, Adv. Mater., 2001, 13, 1266-1269.

34 A. M. Wen and N. F. Steinmetz, Chem. Soc. Rev., 2016, 45, 4074-4126.

35 W. C. Records, Y. Yoon, J. F. Ohmura, N. Chanut and A. M. Belcher, Nano Energy, 2019, 58, 167-174.

36 P. Kramberger, M. Ciringer, A. Strancar and M. Peterka, Virol. J., 2012, 9, 265. 
37 Z. Szakacs, T. Meszaros, M. I. de Jonge and R. E. Gyurcsanyi, Nanoscale, 2018, 10, 13942-13948.

38 M. Gast, H. Sobek and B. Mizaikoff, Hum. Gene Ther: Methods., 2019, 30, 235-244.

39 S. Chatterjee, R. Molenaar, L. Tromp, R. M. Wagterveld, H. D. W. Roesink, J. Cornelissen, M. Claessens and C. Blum, Methods Appl. Fluoresc., 2021, 9, 025001.

40 L. Yang and T. Yamamoto, Front. Microbiol., 2016, 7, 1500.

41 Y. Horiguchi, T. Goda, A. Matsumoto, H. Takeuchi, S. Yamaoka and Y. Miyahara, Langmuir, 2019, 35, 17981806.

42 F. Akpinar and J. Yin, J. Virol. Methods, 2015, 218, 71-76.

43 K. Zhou, L. Li, Z. Tan, A. Zlotnick and S. C. Jacobson, J. Am. Chem. Soc., 2011, 133, 1618-1621.

44 S. T. Lance, D. J. Sukovich, K. M. Stedman and A. R. Abate, Virol. J., 2016, 13, 201.

45 C. P. Brussaard, Appl. Environ. Microbiol., 2004, 70, 15061513.

46 R. Lonsdale, M. G. Pau, M. Oerlemans, C. Ophorst, A. Vooys, M. Havenga, J. Goudsmit, F. UytdeHaag and G. Marzio, J. Virol. Methods, 2003, 110, 67-71.

47 D. Ozcelik, A. Jain, A. Stambaugh, M. A. Stott, J. W. Parks, A. Hawkins and H. Schmidt, Sci. Rep., 2017, 7, 12199.

48 D. Ozcelik, J. W. Parks, T. A. Wall, M. A. Stott, H. Cai, J. W. Parks, A. R. Hawkins and H. Schmidt, Proc. Natl. Acad. Sci. U. S. A., 2015, 112, 12933-12937.

49 J. E. Dick, A. T. Hilterbrand, A. Boika, J. W. Upton and A. J. Bard, Proc. Natl. Acad. Sci. U. S. A., 2015, 112, 53035308.

50 H. Liang, B. Zhou, D. Wu, J. Li and B. Li, Adv. Colloid Interface Sci., 2019, 272, 102019.

51 H. Ejima, J. J. Richardson, K. Liang, J. P. Best, M. P. van Koeverden, G. K. Such, J. Cui and F. Caruso, Science, 2013, 341, 154-157.

52 J. H. Park, A. Boika, H. S. Park, H. C. Lee and A. J. Bard, J. Phys. Chem. C, 2013, 117, 6651-6657.

53 X. Xiao and A. J. Bard, J. Am. Chem. Soc., 2007, 129(31), 9610-9612.

54 X. Xiao, F. F. Fan, J. Zhou and A. J. Bard, J. Am. Chem. Soc., 2008, 130, 16669-16677.
55 X. Xiao, S. Pan, J. S. Jang, F. F. Fan and A. J. Bard, J. Phys. Chem. C, 2009, 113, 14978-14982.

56 S. J. Kwon and A. J. Bard, J. Am. Chem. Soc., 2012, 134, 7102-7108.

57 S. J. Kwon, F. F. Fan and A. J. Bard, J. Am. Chem. Soc., 2010, 132(38), 131265-113167.

58 E. J. Stuart, N. V. Rees, J. T. Cullen and R. G. Compton, Nanoscale, 2013, 5, 174-177.

59 E. J. Stuart, K. Tschulik, D. Omanovic, J. T. Cullen, K. Jurkschat, A. Crossley and R. G. Compton, Nanotechnology, 2013, 24, 444002.

60 E. J. E. Stuart, Y.-G. Zhou, N. V. Rees and R. G. Compton, RSC Adv., 2012, 2, 6879-6884.

61 N. V. Rees, Electrochem. Commun., 2014, 43, 83-86.

62 J. C. Lees, J. Ellison, C. Batchelor-McAuley, K. Tschulik, C. Damm, D. Omanovic and R. G. Compton, ChemPhysChem, 2013, 14, 3895-3897.

63 S. V. Sokolov, S. Eloul, E. Katelhon, C. Batchelor-McAuley and R. G. Compton, Phys. Chem. Chem. Phys., 2016, 19, 2843.

64 W. Cheng and R. G. Compton, TrAC, Trends Anal. Chem., 2014, 58, 79-89.

65 D. Qiu, S. Wang, Y. Zheng and Z. Deng, Nanotechnology, 2013, 24, 505707.

66 D. Wakerley, A. G. Guell, L. A. Hutton, T. S. Miller, A. J. Bard and J. V. Macpherson, Chem. Commun., 2013, 49, 5657-5659.

67 H. Zhou, F.-R. F. Fan and A. J. Bard, J. Phys. Chem. Lett., 2010, 1, 2671-2674.

68 A. Boika, S. N. Thorgaard and A. J. Bard, J. Phys. Chem. B, 2013, 117, 4371-4380.

69 K. R. Short, D. A. Diavatopoulos, R. Thornton, J. Pedersen, R. A. Strugnell, A. K. Wise, P. C. Reading and O. L. Wijburg, J. Infect. Dis., 2011, 204, 1857-1865.

70 P. Terejanszky, I. Makra, P. Furjes and R. E. Gyurcsanyi, Anal. Chem., 2014, 86, 4688-4697.

71 T. Ahmad, J. Nanotechnol., 2014, 2014, 1-11.

72 I. Makra and R. E. Gyurcsányi, Electrochem. Commun., 2014, 43, 55-59.

73 P. Terejánszky, I. Makra, A. Lukács and R. E. Gyurcsányi, Electroanalysis, 2015, 27, 595-601. 